\title{
Mechanisms of allergen-specific desensitization
}

\section{Doctoral Thesis}

Author(s):

Uermösi, Christina

Publication date:

2010

Permanent link:

https://doi.org/10.3929/ethz-a-006372695

Rights / license:

In Copyright - Non-Commercial Use Permitted 
Diss. ETH No. 19375

\section{MECHANISMS OF ALLERGEN-SPECIFIC DESENSITIZATION}

A dissertation submitted to

\section{ETH ZURICH}

For the degree of

Doctor of Sciences

\section{Presented by \\ CHRISTINA UERMÖSI}

Master of Science, University of Constance

Born December $24^{\text {th }}, 1979$

Citizen of Dietikon $(\mathrm{ZH})$

accepted on the recommendation of

Prof. Dr. Annette Oxenius, examiner

Prof. Dr. Manfred Kopf, co-examiner

Dr. Martin F. Bachmann, co-examiner 


\section{SUMMARY}

Protective immunity is provided by the interplay between the innate and the adaptive arms of the immune systems. The innate as well as the adaptive immune response is regulated by specialized cells with the challenging task to eliminate pathogens while not damaging the host itself. Usually the immune system copes well with this charge, but is not always successful. Allergic reactions are representative for such a misregulated immune response: 1) adaptive immune responses are elicited towards harmless antigens such as animal dander or pollen resulting in immunoglobulin $\mathrm{E}(\mathrm{IgE})$ production, 2) cells of the innate system such as mast cells or basophils, which express the high affinity IgE receptor (FceRI), bind these allergenspecific IgE antibodies. If allergen is encountered subsequently, FceRI-bound IgEs are crosslinked, causing activation of mast cells and the release of vasoactive amines and cytokines. Furthermore, proinflammatory lipids, cytokines, and chemokines are produced and released, leading to an allergic inflammation. Although frequency of individuals suffering from allergies has increased exponentially over the last century, the only available therapy that stops disease progression is allergen-specific immunotherapy (SIT). Even though allergenspecific antibodies have been reported to play an important role in SIT, mechanisms of IgGmediated inhibition of allergic reactions are not well defined.

The present studies aimed to provide better understanding of the mechanisms how allergenspecific IgG antibodies may modulate allergic responses. Therefore, we generated monoclonal antibodies (mAbs) that recognize three non-overlapping epitopes on the major cat allergen Feld1. Each of the three mAbs was produced as $\operatorname{IgE}$ or different $\operatorname{IgG}$ isotypes. We found that IgE antibodies against two non-overlapping epitopes on Feld1 were required and sufficient to sensitize mast cells for maximal activation upon exposure to monomeric Feld1. Furthermore, IgG antibodies recognizing a single epitope were able to block mast cell activation by $\operatorname{IgE}$ antibodies recognizing two different epitopes in vitro and in vivo. This inhibition required Fc $\gamma$ receptor IIB (Fc $\gamma$ RIIB) expression by mast cells. Humanized Feld1specific IgGs of a single specificity were able to block degranulation of basophils from individuals with cat allergy. The inhibitory potential of these antibodies increased when larger allergen-IgG complexes were formed. Moreover, Feld1-specific IgG antibodies were able to cause massive internalization of FceRI-bound IgE in vitro and in vivo within one hour. Despite IgE-internalization, little mast cell activation was observed. Unexpectedly, absence of Fc $\gamma$ RIIB reduced IgE internalization but increased mast cell activation. Hence, Fc $\gamma$ RIIB 
promotes IgE internalization whilst inhibiting mast cell activation. Thus, allergen-specific IgG antibodies promote internalization of allergen-specific IgE in the absence of cellular activation due to the engagement of Fc $\gamma$ RIIB.

In a second part of this thesis allergen-specific IgE B cell responses were characterized in vivo in an allergic asthma model where mice were sensitized intranasally with Feld1. Both, IgE and IgG1 Feld1-specific serum titers increased during sensitization. Antigen-specific antibody-forming cells (AFCs) secreting Feld1-specific IgEs and IgGs could be tracked in secondary lymphoid organs and bone marrow with highest numbers in the draining mediastinal lymph nodes. Induction of Feld1-positve germinal centres in the lymph nodes could be observed and up to $25 \%$ of all class switched IgG expressing B cells located in the mediastinal lymph node showed Feld1 specificity. However, class switched IgE-positive B cells were absent or bellow detection levels from secondary lymphoid organs of allergic mice, suggesting that allergen specific IgE B cell responses could differ in kinetics or location from IgG B cell response.

Taken together this thesis provides a better understanding of the mechanism of allergenspecific IgG-mediated protection in allergic responses and describes a novel mechanism of IgG-mediated mast cell desensitization: down-regulation of allergen-specific IgE. 


\section{ZUSAMMENFASSUNG}

Zum Schutz eines Organismus vor Pathogenen ist ein komplexes Zusammenspiel des angeborenen und adaptiven Immunsystems nötig. Sowohl angeborene wie adaptive Immunantworten werden durch spezialisierte Zellen vermittelt, welche die herausfordernde Aufgabe erfüllen müssen, Pathogene zu eliminieren, ohne den Wirtsorganismus selbst zu schädigen. Im Normalfall ist das Immunsystem dieser Aufgaben gewachsen. Bei Fehlregulierungen der Immunantwort kann dies $\mathrm{zu}$ unerwünschten Reaktionen führen. Allergische Reaktionen sind die Folge einer solchen fehlerhaften Immunantwort. In diesem Fall wird eine adaptive Immunantwort gegen harmlose Tierschuppen oder Pollen ausgelöst, welche die Produktion Immunoglobulin E (IgE) auslöst. Die gebildeten IgEs werden auf der Zelloberfläche von Mastzellen und Basophilen mittels FceRI gebunden, ein Rezeptor, der mit hoher Affinität Allergen-spezifische IgE bindet. Bei erneutem Kontakt mit dem Allergen werden die vom FceRI gebundenen IgE vernetzt, was zu einer Zellaktivierung führt. Durch die Aktivierung setzt die Mastzelle vasoaktive Amine und Zytokine frei. Des weitern wird die Synthese und Freisetzung von proinflammatorischen Lipiden, Zytokinen und Chemokinen induziert, welche eine allergische Entzündung auslösen. Obwohl die Anzahl allergischer Personen während des letzten Jahrhunderts exponentiell angestiegen ist, gibt es nur eine Behandlungsmethode, welche Krankheitsverlauft langfristig beinflusst; die Allergenspezifische Immuntherapie (SIT). Während der SIT werden Allergen-spezifische IgGs gebildet, deren schützende Wirkung gegen allergische Reaktionen beschrieben wurde. Der Mechanismus, wie Allergen-spezifische IgG Antikörper allergischen Reaktionen inhibieren können, ist jedoch nur unvollständig bekannt.

Das Ziel der vorliegenden Studie war ein erweitertes Verständnis für den Mechanismus zu erlangen, wie Allergen-spezifische IgG Antikörper allergischen Reaktionen inhibieren können. Für diesen Zweck haben wir drei monoklonale Antikörper (mAk) hergestellt, welche drei nicht überlappende Epitope auf Feld1, dem Hauptallergen von Katzen, erkennen. Jeder der drei mAk wurde als Maus IgE, IgG1 und IgG2a hergestellt. Zwei verschiedene IgE Antikörper waren nötig um Mastzellen zu Sensitisieren und maximale Allergen-vermittelte Aktivierung zu induzieren. Diese durch IgE vermittelte Aktivierung der Mastzellen konnte durch IgG Antikörper, welche das dritte nicht überlappende Feld1-Epitop erkannten, in vitro als auch in vivo inhibiert werden. Diese Inhibition war vom Fcy Rezeptor IIB (Fc $\gamma$ RIIB) abhängig, welcher von Mastzellen exprimiert wird. Zudem konnte gezeigt werden, dass humanisierte, Feld1-spezifische IgG Antikörper, die Degranulation Basophiler, aus dem Blut 
von Katzenallergikern gewonnen wurden, blockieren können. Der Einsatz aller drei Feld1spezifischer IgG Antikörper verstärkte den inhibierenden Effekt. Dies könnte einerseits durch die Bildung grösserer Feld1-IgG Komplexe oder andererseits durch zusätzliche Neutralization des Allergens erklärt werden.

Zusätzlich zu der Inhibition der IgE vermittelten Mastzellaktivierung, vermittelten Feld1spezifische IgG Antikörper innerhalb einer Stunde starke Internalisierung von FceRIgebundenem IgE. Trotz der starken Internalisierung von $\operatorname{IgE}$ konnte nur eine geringe Aktivierung der Mastzellen festgestellt werden. Unerwarteter weise verstärkte die Deletion von FcyRIIB auf Mastzellen deren Aktivierung, wobei die Internalisierung von IgE selbst stark reduziert war. Demzufolge wird durch Bindung von Allergen-spezifischen IgG Antikörpern an FcyRIIB die IgE Internalisierung gefördert ohne eine Aktivierung der Mastzelle auszulösen.

In einem zweiten Teil dieser These wurden Allergen-spezifischen B Zell-Antworten in vivo charakterisiert. Dazu wurde ein Asthma Modell verwendet, in welchem Mäuse intranasal mit Feld1 sensitisiert wurden. Während der Sensitisierung konnte ein Anstieg der Feld1spezifischen IgG1 sowie IgE Antikörpertiter im Serum beobachtet werden. Allergenspezifische Antikörper bildende Zellen (AFCs), welche Feld1-spezifisches IgG und IgE sekretierten, konnten in den sekundären Lymphorganen und im Knochenmark detektiert werden. Die höchste Anzahl wurde im drainierenden mediastinalen Lymphknoten gemessen. Auch die Bildung Feld1-spezifischer Keimzentren konnte im mediastinalen Lymphknoten beobachtet werden, wobei bis $\mathrm{zu} 25 \%$ aller IgG B Zellen Feld1-spezifisch waren. In den sekundären Lymphorganen konnten jedoch keine IgE B Zellen nachgewiesen werden. Diese Daten implizieren, dass sich Allergen-spezifische IgE B Zellantworten möglicherweise räumlich und zeitlich von den IgG B Zellantworten unterscheiden.

Diese These erweitert das Verständnis für den Mechanismus, wie Allergen-spezifische IgG Antikörper in allergischen Reaktionen schützend wirken. Zudem konnte ein neuer Mechanismus der IgG vermittelten Mastzell Desensitisierung beschrieben werden: die IgG vermittelte Internalisierung von Allergen-spezifischem IgE. 